\title{
Phloroglucinol induces apoptosis through the regulation of insulin-like growth factor 1 receptor signaling pathways in human colon cancer HT-29 cells
}

\author{
MI-HYE KANG, IN-HYE KIM and TAEK-JEONG NAM \\ Departments of Food and Life Science, Pukyong National University, Nam-gu, Busan 608-737, Republic of Korea
}

Received April 24, 2014; Accepted May 28, 2014

DOI: $10.3892 /$ ijo.2014.2521

\begin{abstract}
Phloroglucinol is a polyphenol compound with free radical scavenging, anti-inflammatory and antitumor activity. In this study, we investigated the anticancer effects of phloroglucinol on insulin-like growth factor-1 receptor (IGF-1R) signaling in HT-29 human colon cancer cells. Apoptosis was evaluated using 4',6-diamidino-2-phenylindole (DAPI) staining, which clearly demonstrated cell shrinkage and condensed nuclei. Treatment with a pan-caspase inhibitor reduced the expression of phosphatidylinositol-3-kinase (PI3K)/Akt, which could induce apoptosis through IGF-1R signaling pathways. Treatment with phloroglucinol significantly inhibited the expression of Ras, Raf, mitogen-activated protein kinase (MEK), extracellular-signal regulated kinase (ERK) phosphorylation, PI3K and Akt. Phloroglucinol also decreased mammalian target of rapamycin (mTOR) and expression of its downstream effectors p70S6 kinase and translation initiation factors elF4B and RPS6. These results demonstrate that IGF-1R activates PI3K/Akt/mTOR and Ras/ERK-MAPK downstream signaling pathways, which has important implications for understanding the roles of cell growth pathways in colon cancer cell tumorigenesis.
\end{abstract}

\section{Introduction}

Although several therapeutically useful compounds have been identified, their pharmacological properties have been reported using crude extracts $(1,2)$. Phloroglucinol is a multipurpose compound with diverse application as an anti-inflammatory with anticarcinogenic properties that has attracted recent biomedical research interest $(3,4)$. The etiology of cancer involves the

Correspondence to: Professor Taek-Jeong Nam, Departments of Food and Life Science, Pukyong National University, Nam-gu, Busan 608-737, Republic of Korea

E-mail: namtj@pknu.ac.kr

Key words: phloroglucinol, insulin-like growth factor-1 receptor signaling pathway, PI3K/Akt/mTOR signaling pathway, Ras/ERK-MAPK signaling pathway, cell cycle suppression of apoptotic processes and dysregulation of cellular proliferation, leading to tumor development (5). The majority of cancer treatment approaches, such as chemotherapy and radiation therapy, destroy cancer cells by inducing apoptosis $(6,7)$. However, cancer cells often develop resistance and many therapies indirectly activate apoptosis by damaging DNA $(8,9)$.

Insulin-like growth factor-1 (IGF-1) signaling promotes cell growth and is used as a crucial proliferative marker in cancer cells $(10,11)$. The IGF-1 receptor (IGF-1R) has a dominant role in cancer cell survival via autocrine and paracrine mechanisms to promote oncogenesis $(12,13)$. Recruitment of these molecules activates phosphatidylinositol-3-kinase (PI3K)/Akt and Ras/ extracellular signal-regulated kinase (ERK)-mitogen-activated protein kinase (MAPK) signaling pathways (14).

Activation of PI3K converts phosphatidylinositol 4,5-biphosphate (PIP2) into phosphatidylinositol 3,4,5 phosphate (PIP3), which leads to plasma membrane localization of phosphoinositol-dependent kinase-1 (PDK1) via its pleckstrin homology (PH) domain (15). Akt is the major mediator of PI3K signaling with a large number of downstream substrates, including mammalian target of rapamycin (mTOR) (16).

Furthermore, cross-talk between the PI3K/Akt and the Ras/ERK-MAPK pathways is involved in protein translation (17). mTOR and p70S6 kinase (p70S6K) are the primary downstream effectors that activate translation initiation factors and inactivate regulatory proteins targeting translation (18). During apoptosis, Cyclin D activates the cyclin-dependent kinases (Cdks), such as Cdk4 and Cdk6, which mediates oncogenic actions and provides an attractive therapeutic target (19). The current study aimed to investigate the role of phloroglucinol on apoptosis and IGF-1R signaling pathways in HT-29 colon cancer cells as a potential therapeutic target in cancer therapy.

\section{Materials and methods}

Cell culture. HT-29 colon cancer cells (ATCC HTB-38; ATCC, Manassas, VA, USA) were grown in 100-mm culture dishes, containing RPMI-1640 medium supplemented with $10 \%$ fetal bovine serum (FBS) (HyClone, Logan, UT, USA) and penicillin/streptomycin $(\mathrm{P} / \mathrm{S})$. The cells were maintained in a humidified environment under a $5 \% \mathrm{CO}_{2}, 95 \%$ air at $37^{\circ} \mathrm{C}$. The medium was replaced every 2 days and trypsinized when the cells reached $80 \%$ confluence. 
Western blot analysis. HT-29 cells were cultured to $60 \%$ confluence and then incubated in serum-free medium (SFM) for $6 \mathrm{~h}$. Phloroglucinol $(0-50 \mu \mathrm{g} / \mathrm{ml})$ was added to SFM for an additional $24 \mathrm{~h}$. Cell extracts were prepared by washing cultures with phosphate-buffered saline (PBS) and suspending in extraction lysis buffer [20 mM Tris- $\mathrm{HCl}(\mathrm{pH} 7.4), 150 \mathrm{mM} \mathrm{NaCl}, 1 \%$ NP-40, 1 mM EGTA, 1 mM EDTA, 0.25\% Na-deoxycholate, $2.5 \mathrm{mM}$ sodium pyrophosphate] containing protease inhibitors $(1 \mathrm{mM}$ sodium orthovanadate, $1 \mu \mathrm{g} / \mathrm{ml}$ aprotinin, $1 \mu \mathrm{g} / \mathrm{ml}$ pepstatin, $1 \mu \mathrm{g} / \mathrm{ml}$ leupeptin, $1 \mathrm{mM} \mathrm{NaF}, 1 \mathrm{mM} \mathrm{PMSF}$ ) on ice. Cell extracts were centrifuged at 12,000 rpm for $10 \mathrm{~min}$ and the supernatant was used for western blotting. Sample buffer was added to the total cell lysate, and the mixed samples were boiled for $10 \mathrm{~min}$ at $100^{\circ} \mathrm{C}$. Proteins were separated in $5-15 \%$ SDS-PAGE and transferred onto polyvinylidene fluoride membranes (Millipore, Billerica, MA, USA). Membranes were blocked for $90 \mathrm{~min}$ at room temperature in blocking buffer [1\% bovine serum albumin (BSA) in TBS-T], followed by incubation with primary antibodies $(1: 1,000$ in $1 \%$ BSA/TBS-T) overnight at $4^{\circ} \mathrm{C}$ or for $150 \mathrm{~min}$ at room temperature. The membranes were then washed three times for $10 \mathrm{~min}$ in TBS-T and incubated with horseradish peroxidase-conjugated goat, mouse, or rabbit secondary antibodies (1:10,000 in 1\% BSA/TBS-T). Immunoreactive bands were detected using an enhanced chemiluminescence western blotting kit (Amersham Biosciences, Piscataway, NJ, USA).

Cell cycle analysis. The effect of phloroglucinol on cell cycle progression was determined using a Muse ${ }^{\mathrm{TM}}$ cell cycle analyzer from Millipore (EMD Millipore Co., Hayward, CA, USA). The cells were cultured in 6-well plates grown to $60 \%$ confluence and incubated in SFM for $6 \mathrm{~h}$, followed by incubation with phloroglucinol $(0-50 \mu \mathrm{g} / \mathrm{ml})$ for $24 \mathrm{~h}$. Cells were collected in $1 \%$ FBS-RPMI-1640 medium, and test reagent was added to each respective tube. Cells were mixed by vortexing and the reaction was incubated for $30 \mathrm{~min}$ at room temperature in the dark. Following treatment, cells were stained to evaluate the $\mathrm{G} 0 / \mathrm{G} 1, \mathrm{~S}$ and $\mathrm{G} 2 / \mathrm{M}$ phase rates.

mRNA expression analysis. The mRNA expression levels of specific genes were measured by reverse transcriptionpolymerase chain reaction (RT-PCR). HT-29 cells were seeded onto 6 -well plates at $2 \times 10^{4}$ cells/well in $2 \mathrm{ml}$ of medium. Cells were cultured for 2 days and the medium was replaced with SFM for $6 \mathrm{~h}$, followed by treatment with phloroglucinol $(0-50 \mu \mathrm{g} / \mathrm{ml})$ for $24 \mathrm{~h}$. Cells were treated with $1 \mathrm{ml}$ TRIzol reagent (Invitrogen, Carlsbad, CA, USA), and cDNA was synthesized using the oligo(dt) primer (iNtRON Biotechnology, Seongnam, Korea). The converted cDNA was added to $2 \mathrm{X}$ TOPsimple ${ }^{\mathrm{TM}}$ DyeMIX-nTaq (Enzynomics, Daejeon, Korea) and the primer (Table I) was dissolved in $0.1 \%$ diethylpyrocarbonate (DEPC) water before adding to the reaction mixture. The amplified products were separated on a $1 \%$ agarose gel stained with Redsafe ${ }^{\mathrm{TM}}$ nucleic acid staining solution (iNtRON Biotechnology).

4',6-Diamidino-2-phenylindole (DAPI) staining assay. The cells were grown to subconfluency on 12-mm coverslips and exposed to phloroglucinol for $24 \mathrm{~h}$. The monolayer of cells was washed with PBS and fixed with $1 \%$ paraformal-
Table I. Oligonucleotide sequences of the primer used in RT-PCR analyses.

\begin{tabular}{|c|c|}
\hline \multicolumn{2}{|r|}{ Primer sequence } \\
\hline \multicolumn{2}{|l|}{ PI3K } \\
\hline $\mathrm{F}$ & 5'-AGG AGC GGT ACA GCA AAG AA-3' \\
\hline $\mathrm{R}$ & 5'-GCC GAA CAC CTT TTT GAG TC-3' \\
\hline \multicolumn{2}{|l|}{ Akt } \\
\hline $\mathrm{F}$ & 5'-CAA CTT CTC TGT GGC GCA GTG-3' \\
\hline $\mathrm{R}$ & 5'-GAC AGG TGG AAG AAC AGC TCG-3' \\
\hline \multicolumn{2}{|l|}{ PTEN } \\
\hline $\mathrm{F}$ & 5'-TGG AAA GGG ACG AAC TGG TG-3' \\
\hline $\mathrm{R}$ & 5'-CAT AGC GCC TCT GAC TGG GA-3' \\
\hline \multicolumn{2}{|l|}{ PDK1 } \\
\hline $\mathrm{F}$ & 5'-AAG GGT ACG GGC CTC TCA AA-3' \\
\hline $\mathrm{R}$ & 5'-CCC ACG TGA TGG ACT CAA AGA-3' \\
\hline \multicolumn{2}{|c|}{ mTOR } \\
\hline $\mathrm{F}$ & 5'-CGC TGT CAT CCC TTT ATC G-3' \\
\hline $\mathrm{R}$ & 5'-ATG CTC AAA CAC CTC CAC C-3' \\
\hline \multicolumn{2}{|c|}{ p70S6K } \\
\hline $\mathrm{F}$ & 5'-TAC TTC GGG TAC TTG GTAA-3' \\
\hline $\mathrm{R}$ & 5'-GAT GAA GGG ATG CTT TAC T-3' \\
\hline \multicolumn{2}{|l|}{ RPS6 } \\
\hline $\mathrm{F}$ & 5'-AAG GAG AGA AGG ATA TTC CTG GAC-3' \\
\hline $\mathrm{R}$ & 5'-AGA GAG ATT GAA AAG TTT GCG GAT-3' \\
\hline \multicolumn{2}{|l|}{ Ras } \\
\hline $\mathrm{F}$ & 5'-CCC GTC CTC ATG TAC TGG TC-3' \\
\hline $\mathrm{R}$ & 5'-ATC TTG GAT ACG GCA GGT CA-3' \\
\hline \multicolumn{2}{|l|}{ Raf } \\
\hline $\mathrm{F}$ & 5'-GAT GAT GGC AAA CTC ACG GAT TC-3' \\
\hline $\mathrm{R}$ & 5'-AAG GCA GTC GTG CAA GCT CA-3' \\
\hline \multicolumn{2}{|l|}{ MEK } \\
\hline $\mathrm{F}$ & 5'-CGATGGATCCCCCAAGAAGAAGCCGAC G-3' \\
\hline $\mathrm{R}$ & 5'-CGATCTCGAGTTAGACGCCAGCAGCAT G-3' \\
\hline \multicolumn{2}{|c|}{ GAPDH } \\
\hline $\mathrm{F}$ & 5'-CAG CCG AGC CAC ATC G-3' \\
\hline $\mathrm{R}$ & 5'-TGA GGC TGT TGT CAT ACT TCT C-3' \\
\hline
\end{tabular}

F, forward; R, reverse.

dehyde for $10 \mathrm{~min}$ at room temperature. Fixed cells were permeabilized with $0.2 \%$ Triton $\mathrm{X}-100$ in PBS for $10 \mathrm{~min}$ at room temperature and incubated with $1 \mu \mathrm{g} / \mathrm{ml}$ of DAPI for $5 \mathrm{~min}$. The condensed chromatin and fragmented nuclei in DAPI-stained apoptotic cells were viewed under a confocal microscope.

Statistical analysis. Study results were analyzed using SPSS software (ver. 18.0; SPSS, Inc., Chicago, IL, USA). Data are presented as means \pm standard deviation. Duncan's multiple 


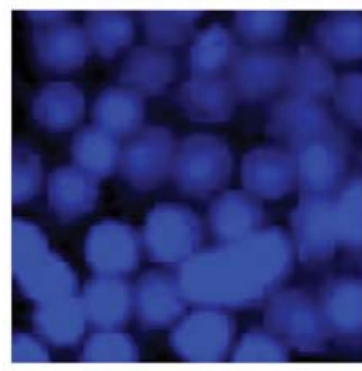

0

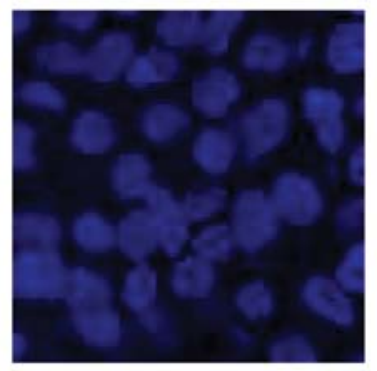

12.5

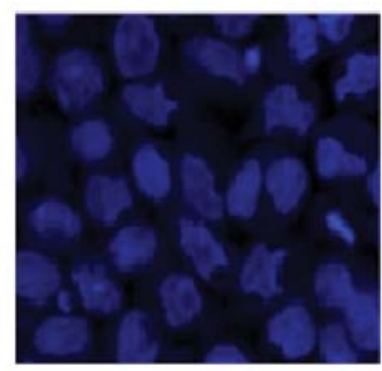

25

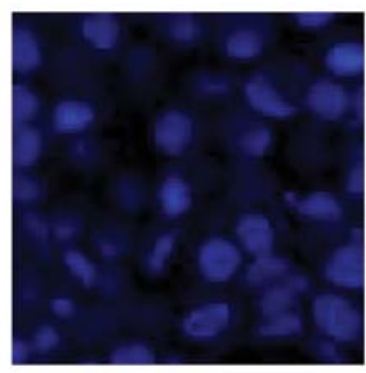

50

Phloroglucinol $(\mu \mathrm{g} / \mathrm{ml})$

Figure 1. Phloroglucinol-induced apoptosis in HT-29 colon cancer cells. HT-29 cells were treated with phloroglucinol $(0,12.5,25 \mathrm{and} 50 \mu \mathrm{g} / \mathrm{ml})$ for $24 \mathrm{~h}$ before chromatin staining with 4',6-diamidino-2-phenylindole (DAPI). Apoptotic cells were imaged with a confocal laser microscope using a x40 objective.
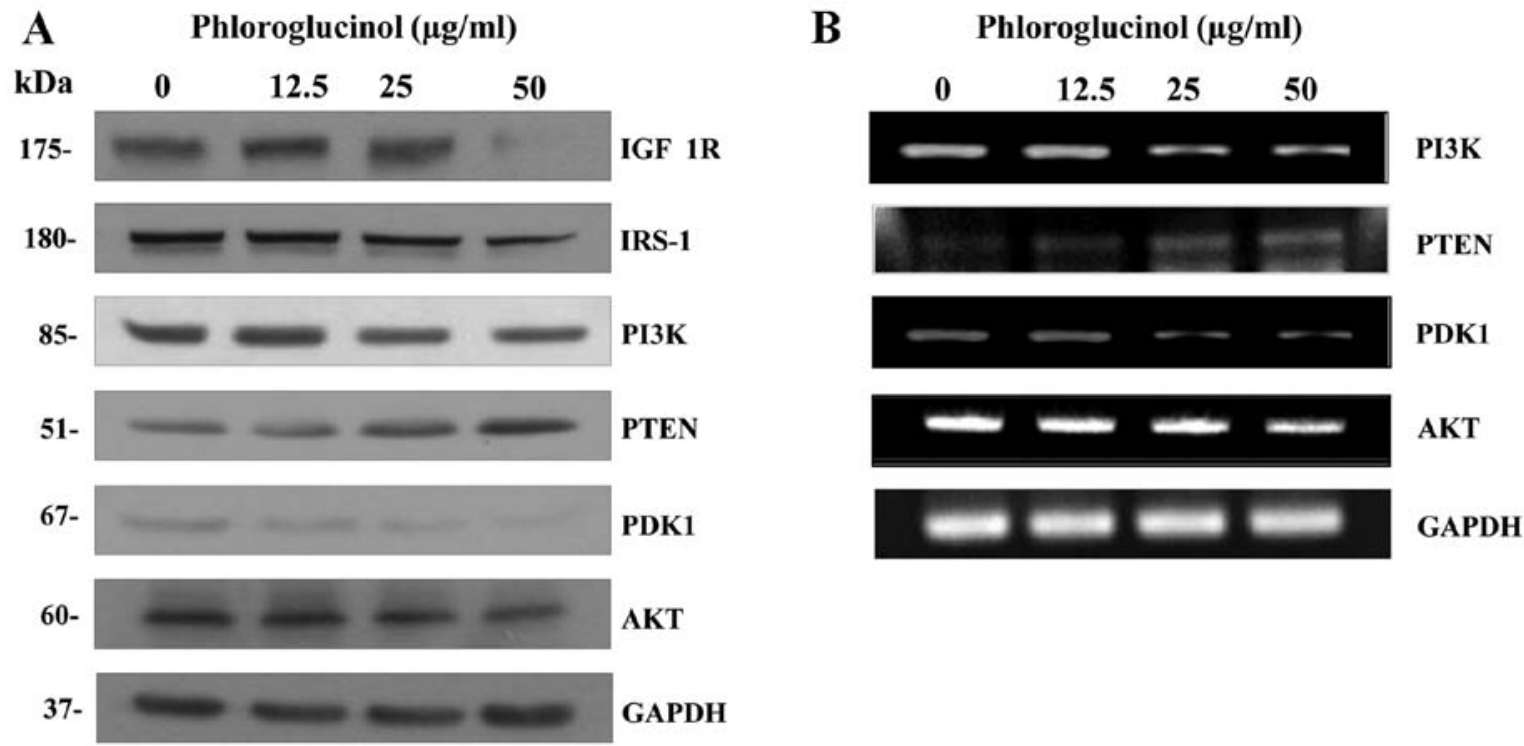

Figure 2. Effect of phloroglucinol on the (A) protein and (B) mRNA expression of IGF-1R, IRS-1, PI3K, PTEN, PDK-1 and Akt in HT-29 cells. Cells were treated with phloroglucinol $(0,12.5,25$ and $50 \mu \mathrm{g} / \mathrm{ml})$ for $24 \mathrm{~h}$. Glyceraldehyde 3-phosphate dehydrogenase (GAPDH) was used as a loading control. Data are representative of three different experiments.

range test was used to calculate differences between values. Statistical significance was indicated at $\mathrm{P}<0.05$.

\section{Results}

Phloroglucinol induces nuclear hallmarks of apoptosis in HT-29 cells. To view apoptotic body formation and nuclear morphological changes characteristic of apoptosis, HT-29 cells were treated with phloroglucinol $(0,12.5,25$ and $50 \mu \mathrm{g} / \mathrm{ml})$ for $24 \mathrm{~h}$ and stained with DAPI. Chromatin was visualized by confocal microscopy. Untreated cells exhibited swelling and increased homogenous chromatin morphology, while phloroglucinol-treated cells exhibited fragmented nuclei with densely stained granular condensed chromatin (Fig. 1).

Phloroglucinol inhibits HT-29 cell growth by suppressing $I G F-1 R$ signaling. Activation of IGF-1R signaling includes PI3K and MAPK pathways (20), which can be regulated by IGF binding proteins. To examine the potential role of PI3K and
Akt signaling in mediating the effects of phloroglucinol, we performed western blots (Fig. 2A) and RT-PCR (Fig. 2B) analysis. A 24-h treatment with phloroglucinol dose-dependently suppressed expression of IGF-1R protein and downstream signaling proteins such as insulin receptor substrate-1 (IRS-1), PI3K, Akt and PDK1. These results indicate that phloroglucinol could inhibit IGF-1R signaling related molecules, as well as activate the PI3K and Akt pathway.

Caspase activation inhibits effects of phloroglucinol on IGF-1R-regulated proteins. Previous studies have shown that phloroglucinol induced apoptosis via Fas-induced signaling pathways, and results from this study confirmed that phloroglucinol downregulated IGF-1R-related proteins such as PI3K and Akt. To determine whether Fas-mediated apoptosis inhibited IGF-1R signaling pathways, HT-29 cells were treated with a pan-caspase inhibitor, which diminished caspase activation and suppressed PI3K and Akt expression levels (Fig. 3). Thus, IGF-1R signaling is a target of phloroglucinol-induced apoptosis. 


\section{Phloroglucinol $(\mu \mathrm{g} / \mathrm{ml})$}

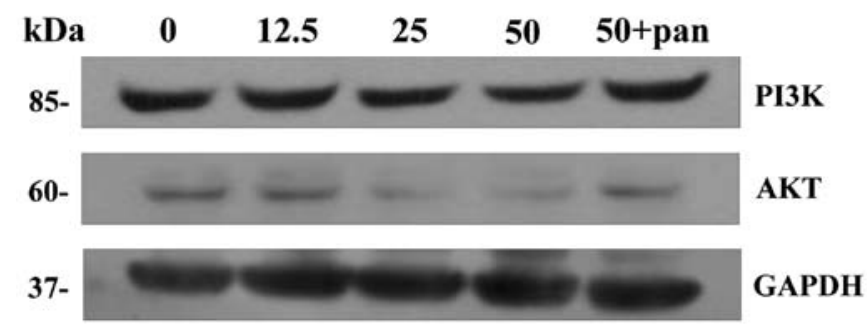

Figure 3. Effect of phloroglucinol on the pan-caspase inhibitor-induced activation of PI3K and Akt in HT-29 cells. Phloroglucinol was added at 0 , $12.5,25$ and $50 \mu \mathrm{g} / \mathrm{ml}$. HT-29 cells treated with $50 \mu \mathrm{g} / \mathrm{ml}$ phloroglucinol were also treated for $1 \mathrm{~h}$ with the pan-caspase inhibitor Z-VAD (Ome)-FMK. Each band depicts the quantitative analysis from western blots.

Phloroglucinol inhibits HT-29 cell survival by suppressing mTOR signaling pathways. Phloroglucinol decreased Akt levels, which has been reported to be phosphatase and tensin homolog (PTEN)-dependent. Therefore, we examined the effect of phloroglucinol on mTOR/p70S6K signaling pathways that regulate cell growth. Phloroglucinol suppressed protein (Fig. 4A) and mRNA (Fig. 4B) expression of mTOR and p70S6K, as well as the translation initiation factors elF4B and RPS6. Collectively, these data indicate that phloroglucinol effectively decreases mTOR/p70S6K growth signaling pathways in colon cancer HT-29 cells.

Phloroglucinol inhibits HT-29 cell growth by suppressing ERK-MAPK signaling pathways. IGF-1R protein and mRNA expression decreased significantly after $24 \mathrm{~h}$ of phloroglucinol treatment in HT-29 colon cancer cells. IGF-1R signaling involves activation of Ras, Raf, MEK and ERK (21), and we determined that protein (Fig. 5A) and mRNA (Fig. 5B) expression levels of Ras, Raf, MEK and phosphorylated ERK were suppressed in phloroglucinol-treated HT-29 compared with control cells. These results demonstrate that phloroglucinol inhibits Ras/ERK-MAPK growth signaling pathways in HT-29 cells.

Effects of phloroglucinol on cell cycle progression in HT-29 cells. Phloroglucinol-induced apoptosis was sustained via cell cycle arrest (Fig. 6). Phloroglucinol increased the ratio of cells in the G0 and G1 phase, while decreasing the ratio of cells in the $\mathrm{G} 2$ and $\mathrm{M}$ phases, suggesting that phloroglucinol inhibits cell cycle progression to stimulate apoptosis.

Effects of phloroglucinol on cell cycle-related proteins. To identify the mechanisms mediating phloroglucinol-induced cell cycle arrest, we examined the expression of cell cycle regulatory proteins. Western blot analysis results indicated that the expression of Cdk4, Cdk6, pRb and Cyclin D, which regulate the $\mathrm{G} 0$ and $\mathrm{G} 1$ phases, decreased with phloroglucinol treatment. However, the levels of p21 and p27 were dosedependently increased following treatment with phloroglucinol (Fig. 7). Taken collectively, these results demonstrate that phloroglucinol inhibits HT-29 cell proliferation by modulating cell cycle-related proteins.

\section{Discussion}

Previous results suggested that phloroglucinol inhibited growth of HT-29 cells via IGF-1R-mediated signaling pathways. In this study, we confirmed that phloroglucinol induced apoptosis and inhibited cell cycle progression by regulating PI3K/Akt/mTOR and Ras/ERK-MAPK signaling pathways. IGF-1R and apoptotic pathways play important roles in cancer progression (19). Reduced expression of IGF-1R and downstream regulatory proteins inhibits the development of cancer, and the results presented here demonstrated that phloroglucinol inhibited cancer by regulating IGF-1R pathways (Fig. 2). As shown in Fig. 3, a pan-caspase inhibitor suppressed caspase activation and affected the level of IGF-1R-mediated PI3K/Akt signaling proteins. Furthermore, we demonstrated that apoptosis-mediated Fas signaling activity was inhibited by IGF-1R.

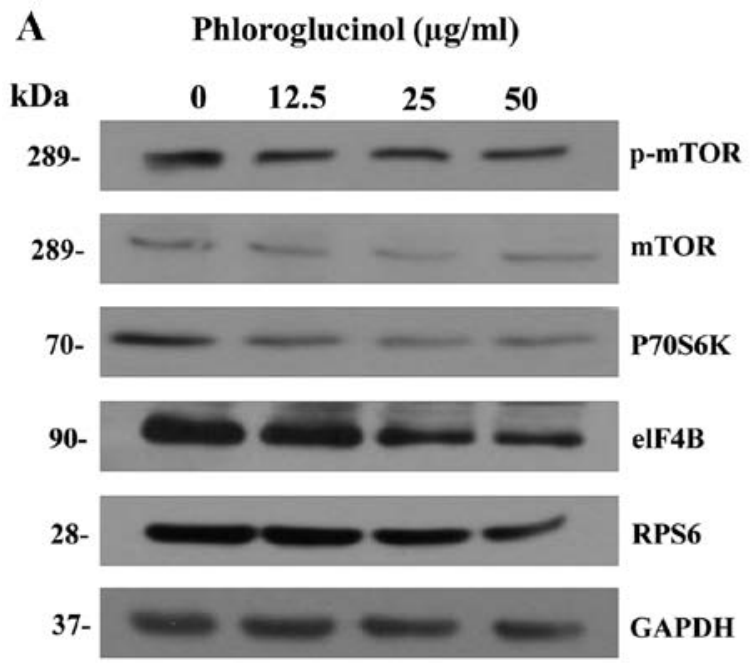

B

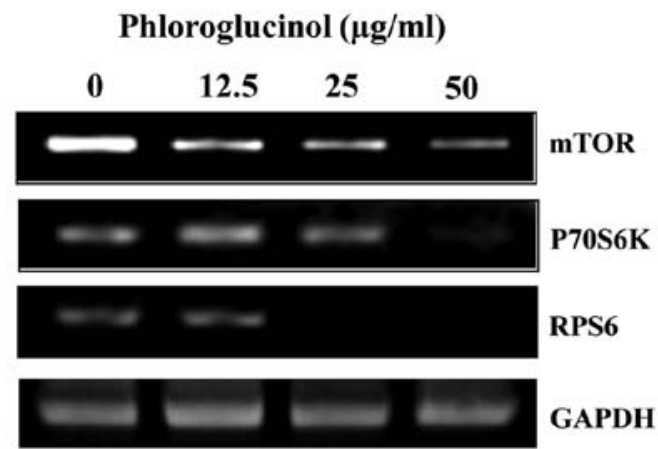


A

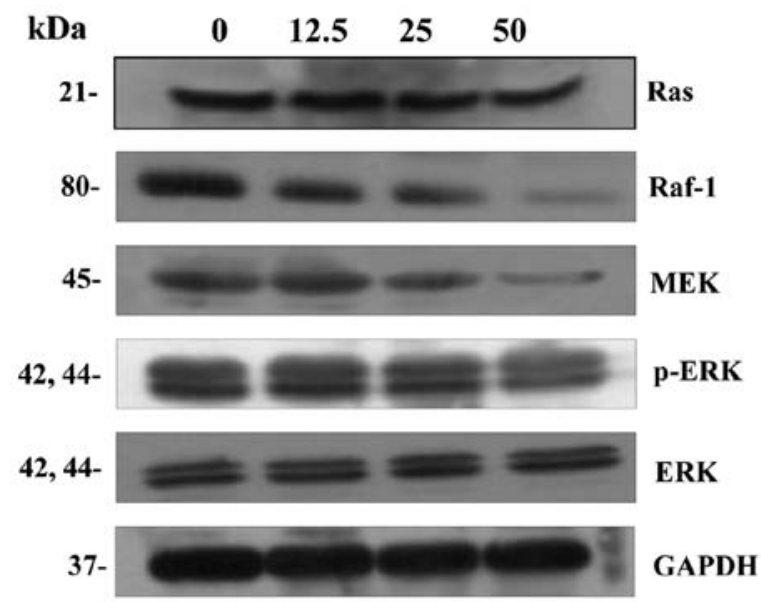

B Phloroglucinol $(\mu \mathrm{g} / \mathrm{ml})$

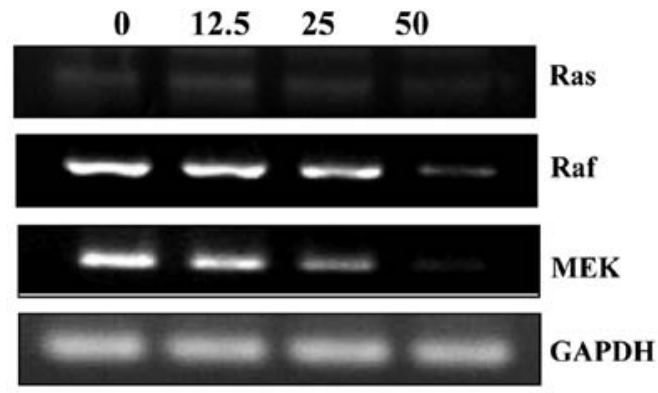

Figure 5. Dose-dependent effect of phloroglucinol on the (A) protein and (B) mRNA expression of Ras, Raf, MEK and phospho-ERK in HT-29 colon cancer cells.

A

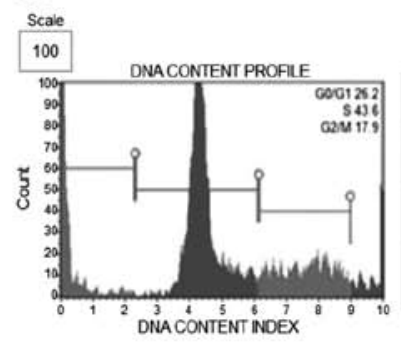

C

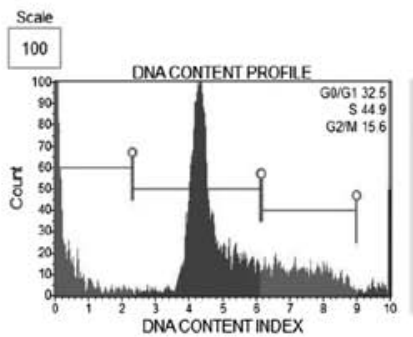

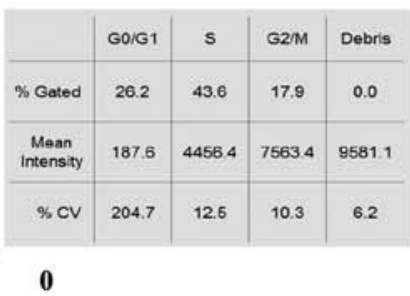

0

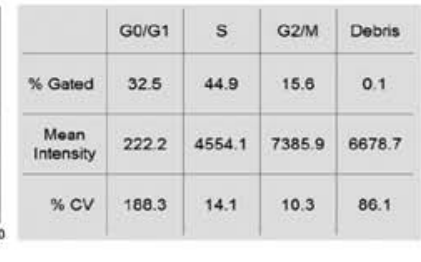

25
B
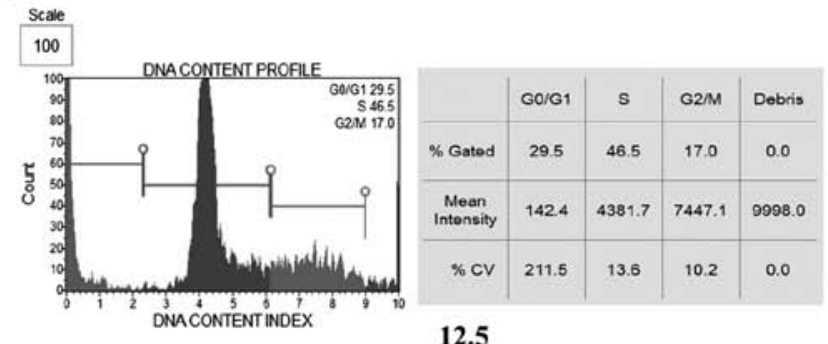

12.5

D

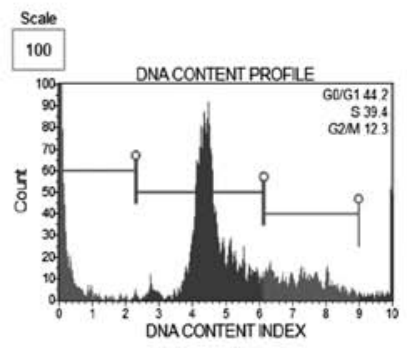

50

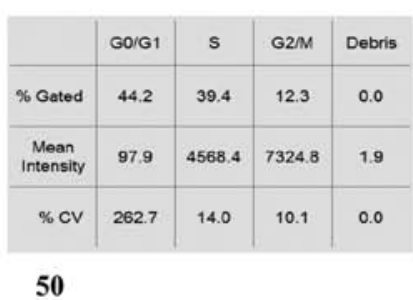

Phloroglucinol $(\mu \mathrm{g} / \mathrm{ml})$

Figure 6. Cell cycle analysis revealed that phloroglucinol induced G0 and G1 cell cycle arrest in a dose-dependent manner in HT-29 cells

IGF and IGF-1 receptors represent a group of biological growth transducers involved in diverse pathological processes (20). IGF-1R is auto-phosphorylated by its intrinsic tyrosine kinase activity to facilitate activation of downstream signaling molecules. Activated 1GF-1R and phosphorylated adaptor proteins, such as IRS-1, are coupled to the PI3K/Akt pathway $(21,22)$. PI3K/Akt signaling, along with mTOR/p70S6K, are the primary downstream effectors that activate translation initiation factors and inactivate their regulators (23). In addition, these pathways participate in cross-talk with Ras/ERK-MAPK pathways (24). The present results indicated that phloroglucinol inhibited IGF-1R signaling via mTOR, p70S6K, as well as Ras, Raf, MEK and phosphorylated ERK molecules (Figs. 4 and 5). The study findings also revealed an increase in the percentage of cells in the G0 and G1 phase from 26.2 to $44.2 \%$, while the percentage of cells in the remaining phases decreased following treatment with phloroglucinol from 17.9 to $12.3 \%$, suggesting that phloroglucinol inhibited cell cycle progression (Fig. 6). Phloroglucinol-mediated cell cycle arrest was the result of apoptosis and related to the expression of cyclins and Cdk cell cycle regulatory proteins (Fig. 7). Thus, phloroglucinol-induced cell cycle arrest resulted in cell death in proliferative HT-29 colon cancer cells. 


\section{Phloroglucinol $(\mu \mathrm{g} / \mathrm{ml})$}

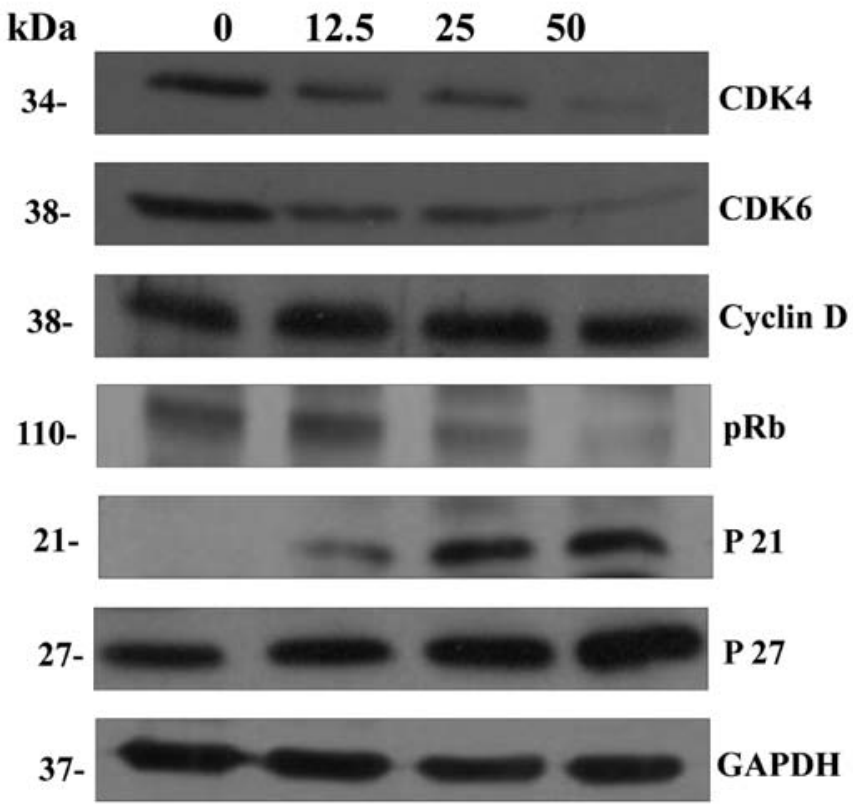

Figure 7. Effect of phloroglucinol on the expression of cell cycle regulated proteins in HT-29 cells. Cells were treated with phloroglucinol $(0,12.5,25$ and $50 \mu \mathrm{g} / \mathrm{ml}$ ) for $24 \mathrm{~h}$ and total protein extracts were subjected to western blot analysis using antibodies against Cdk4, Cdk6, Cyclin D, pRb, p21 and p27.

The extracellular domain of the IGF receptor is responsible for ligand binding, inducing the formation of receptor dimers, and the phosphorylation of tyrosine residues in the cytoplasmic domain of the receptor through activation of an intrinsic kinase. The phosphorylated tyrosine residues play a critical role in intracellular signaling. In cancer cells,
IGF-1R activates IRS-1 by stimulating several intracellular signaling proteins such as PI3K and Akt kinase (25-27). Our results provide mechanistic evidence regarding IGF-1R regulated signaling that includes the PI3K/Akt/mTOR and Ras/ERK-MAPK pathways. mTOR is a serine/threonine protein kinase that integrates nutrient availability with growth factor signaling used to modulate cell proliferation and function (28). Interpretation of these results is complicated by the common regulatory molecules involved in apoptosis, such as caspase and the PI3K/Akt/mTOR signaling pathway. The PI3K/Akt/mTOR signaling pathway is known to play a key role in cell survival, differentiation and metabolism. Videlicet, an inhibitor of the PI3K/Akt/mTOR signaling pathway, caused cell death associated with apoptosis $(29,30)$. The current results indicate that IGF-1 receptor regulated Akt and mTOR, as well as other important molecules such as PTEN, PDK-1 and p70S6K involved in PI3K/Akt/mTOR signaling (Fig. 8).

Likewise, Ras signaling is enhanced due to upstream events, such as the activation of IGF-1R (31). Regardless of the mechanism, augmented Ras signaling contributes to a molecular signature for colon cancers. Ras is a significant oncogene product involved in the pathogenesis of cancers, and expression of activated Ras is sufficient to induce oncogenesis in both normal and cancer cells, supporting the use of common downstream pathways $(32,33)$. Ras transmits a signal to the serine/threonine kinase Raf, which subsequently activates MAPK, resulting in cell growth via the transcriptional activation of multiplex targets (34). Our results demonstrated that IGR-1R modulated Ras, Raf, MEK and phosphorylated ERK to suppress the survival of HT-29 colon cancer cells (Fig. 8).

In conclusion, we have demonstrated that phloroglucinol induced apoptosis via an apoptotic pathway involving growth factors, accounting for the effect of phloroglucinol on IGF-1R regulated signaling pathways in HT-29 colon cancer cells.

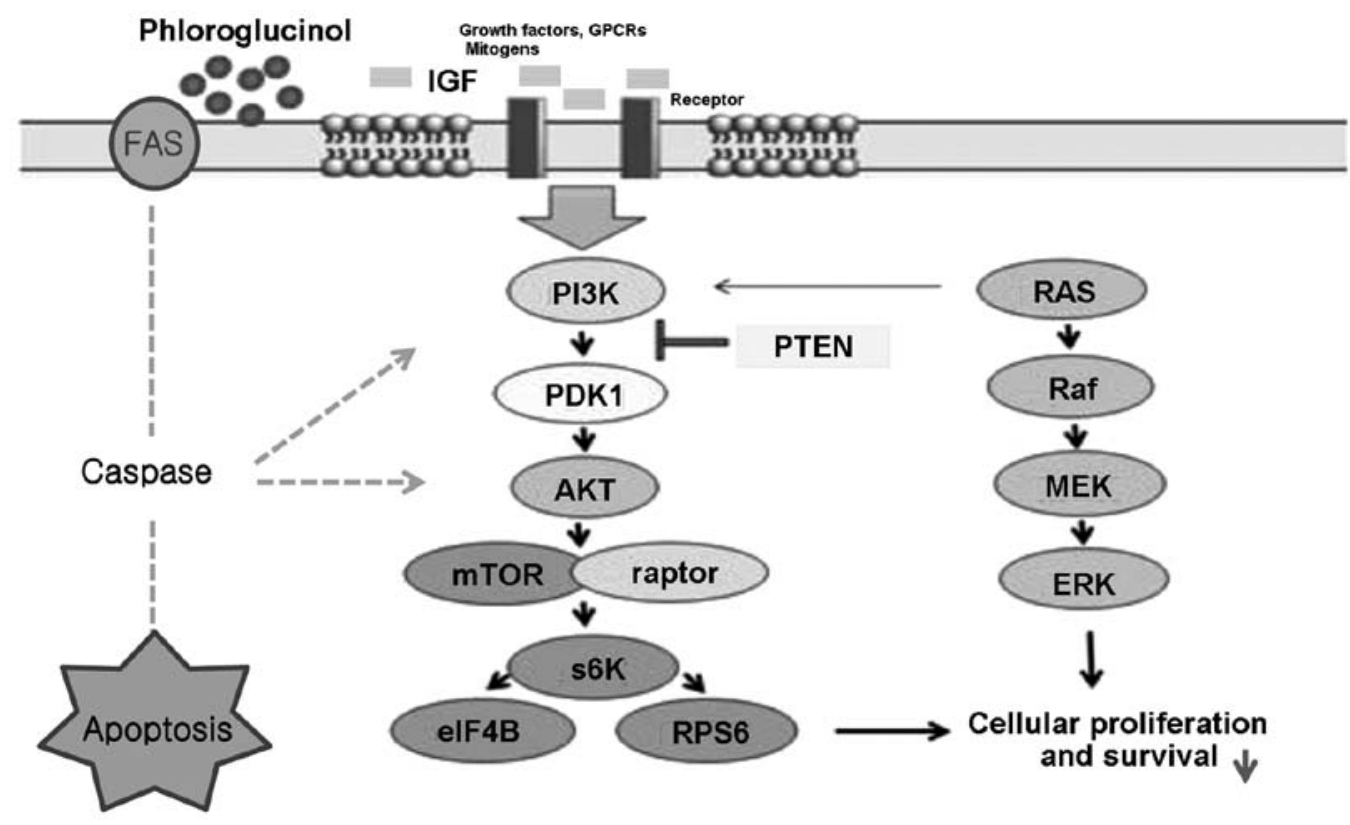

Figure 8. Proposed mechanism of IGF-1R-mediated activation of PI3K/Akt and Ras/ERK-MAPK signaling. The downstream effectors of PI3K/Akt included mTOR/p70S6K and the translation initiation factors elF4B and RPS6. 
These findings suggest a vital role for IGF-1R in colon cancer tumorigenesis, as well as the potential value of phloroglucinol as a therapeutic agent with anticancer effects on human colon cancer.

\section{Acknowledgements}

This research was supported by Fishery Commercialization Technology Development Program through iPET (Korea Institute of Planning and Evaluation for Technology in Food, Agriculture, Forestry and Fisheries) funded by Ministry of Oceans and Fisheries (MOF) (111090-03-3-HD110).

\section{References}

1. Matsui T, Omura K, Kawakami K, Morita S and Sakamoto J: Genotype of thymidylate synthase likely to affect efficacy of adjuvant 5-FU based chemotherapy in colon cancer. Oncol Rep 16: $1111-1115,2006$

2. Oehler C and Ciernik IF: Radiation therapy and combined modality treatment of gastrointestinal carcinomas. Cancer Treat Rev 32: 119-138, 2006.

3. Nagayama K, lwamura K, Shibata T, Hirayama I and Nakamura T: Bactericidal activity of phlorotannins from the brown alga Ecklonia kurom. J Antimicrob Chemother 50: 889-893, 2002.

4. Park EJ and Pezzuto JM: Botanicals in cancer chemoprevention. Cancer Metast Rev 21: 231-255, 2002.

5. Stan SD, Kar S, Stoner GD and Singh SV: Bioactive food components and cancer risk reduction. J Cell Biochem 104: 339-356, 2008.

6. Wei A, Zhou D, Xiong C, Cai Y and Ruan J: A novel nonaromatic $\beta$-ring flavonoid: isolation, structure elucidation and its induction of apoptosis in human colon HT-29 tumor cell via the reactive oxygen species-mitochondrial dysfunction and MAPK activation. Food Chem Toxicol 49: 2445-2452, 2011.

7. Hsu HF, Houng JY, Kuo CF, Tsao N and Wua YC: Glossogin, a novel phenylpropanoid from Glossogyne tenuifolia, induced apoptosis in A549 lung cancer cells. Food Chem Toxicol 46: 3785-3791, 2008.

8. Kang HS, Chung HY, Kim JY, Son BW, Jung HA and Choi JS: Inhibitory phlorotannins from the edible brown alga Ecklonia stolonifera on total reactive oxygen species (ROS) generation. Arch Pharm Res 27: 194-198, 2004.

9. Kim MM, Ta QV, Mendis E, Rajapakse N, Jung WK, Byun HG, Jeon YJ and Kim SK: Phlorotannins in Ecklonia cava extract inhibit matrix metalloproteinase activity. Life Sci 79: 1436-1443, 2006.

10. Lin ML, Chen SS, Lu YC, Liang RY, Ho YT, Yang CY and Chung JG: Rhein induces apoptosis through induction of endoplasmic reticulum stress and $\mathrm{Ca}^{2+}$-dependent mitochondrial death pathway in human nasopharyngeal carcinoma cells. Anticancer Res 27: 3313-3322, 2007.

11. Debatin KM and Krammer PH: Death receptors in chemotherapy and cancer. Oncogene 23: 2950-2966, 2004.

12. Hu W, Lee SK, Jung MJ, Heo SI, Hur JH and Wang MH: Induction of cell cycle arrest and apoptosis by the ethyl acetate fraction of Kalopanax pictus leaves in human colon cancer cells. Bio Resour Technol 101: 9366-9372, 2010.

13. Degterev A and Yuan J: Expansion and evolution of cell death programmes. Nat Rev Mol Cell Biol 9: 378-390, 2008.

14. Tan ML, Ooi JP, Ismail N, Moad Al and Muhammad TS Programmed cell death pathways and current antitumor targets. Pharm Res 26: 1547-1560, 2009.
15. Maddika S, Ande SR, Wiechec E, Hansen LL, Wesselborg S and Los M: Akt-mediated phosphorylation of CDK2 regulates its dual role in cell cycle progression and apoptosis. J Cell Sci 121: 979-988, 2008

16. Hengartner MO: The biochemistry of apoptosis. Nature 407: 770-776, 2000.

17. Grimm S and Brdiczka D: The permeability transition pore in cell death. Apoptosis 12: 841-855, 2007.

18. Cryns V and Yuan J: Proteases to die for. Genes Dev 12: 1551-1570, 1998.

19. Cantley LC: The phosphoinositide 3-kinase pathway. Science 296: 1655-1657, 2002.

20. Sachdev D, Li SL, Hartell JS, Fujita-Yamaguchi Y, Miller JS and Yee D: A chimeric humanized single chain antibody against the type I insulin-like growth factor (IGF) receptor renders breast cancer cells refractory to the mitogenic effects of IGF-1. Cancer Res 63: 627-635, 2003.

21. Segrelles C, Moral M, Lara MF, Ruiz S, Santos M, Leis H, Garcia-Escudero R, Martinez-Cruz AB, Martinez-Palacio J, Hernandez P, Ballestin C and Paramio JM: Molecular determinants of Akt-induced keratinocyte transformation. Oncogene 25: 1174-1185, 2006.

22. Lee ER, Kim JY, Kang YJ, Ahn JY, Kim JH, Kim BW, Choi HY, Jeong MY and Cho SG: Interplay between PI3K/Akt and MAPK signaling pathways in DNA-damaging drug-induced apoptosis. Biochim Biophys Acta 1763: 958-968, 2006.

23. Shaw RJ and Cantley LC: Ras, PI(3)K and mTOR signaling controls tumour cell growth. Nature 441: 424-430, 2006.

24. Bhandari BK, Feliers D, Duraisamy S, Stewart JL, Gingras AC, Abboud HE, Choudhury GG, Sonenberg N and Kasinath BS: Insulin regulation of protein translation repressor $4 \mathrm{E}-\mathrm{BP} 1$, an elF4E-binding protein, in renal epithelial cells. Kidney Int 59: 866-875, 2001.

25. Oldham S and Hafen E: Insulin/IGF and target of rapamycin signaling: ATOR de force in growth control. Trends Cell Biol 13: 79-85, 2003.

26. Bjornsti MA and Houghton PJ: The TOR pathway: a target for cancer therapy. Nat Rev Cancer 4: 335-348, 2004.

27. White MF: The IRS-signaling system: a network of docking proteins that mediate insulin and cytokine action. Recent Prog Horm Res 53: 119-138, 1998.

28. Mori H, Inoki K, Opland D, Munzberg H, Villanueva EC, Faouzi M, Guan KL, et al: Critical roles for the TSC-mTOR pathway in $\beta$-cell function. Am J Physiol Endocrinol Metab 297: E1013-E1022, 2009.

29. Wan X, Harkavy B, Shen N, Grohar P and Helman L: Rapamycin induces feedback activation of Akt signaling through an IGF-1R dependent mechanism. Oncogene 26: 1932-1940, 2007.

30. O'Reilly KE, Rojo F, She QB, Solit D, Mills GB, Smith D, Lane H, Hofmann F, et al: mTOR inhibition induces upstream receptor tyrosine kinase signaling and activates Akt. Cancer Res 66: 1500-1508, 2006.

31. Quevedo C, Salinas M and Alcazar A: Regulation of capdependent translation by insulin-like growth factor-1 in neuronal cells. Biochem Biophys Res Commun 291: 560-566, 2002.

32. Roux PP, Shahbazian D, Vu H, Holz MK, Cohen MS, Taunton J, Sonenberg $\mathrm{N}$ and Blenis $\mathrm{J}$ : RAS/ERK signaling promotes site-specific ribosomal protein S6 phosphorylation via RSK and stimulates cap-dependent translation. J Biol Chem 282: 14056-14064, 2007.

33. Kiaris H and Spandidos D: Mutations of ras genes in human tumors (review). Int J Oncol 7: 413-421, 1995.

34. Treisman R: Regulation of transcription by MAP kinase cascades. Curr Opin Cell Biol 8: 205-215, 1996. 